\title{
Prostat kanseri teşhisi için soft expert kümelere dayanan karar verme probleminin bir uygulamas 1
}

\author{
Zehra GÜZEL ERGÜL ${ }^{1, *}$, Naime DEMIRTAŞ² \\ ${ }^{1}$ Kırşsehir Ahi Evran Üniversitesi Fen Edebiyat Fak. Matematik Böl., Bağbaşı kampüsü, Kırşsehir. \\ ${ }^{2}$ Mersin Üniversitesi Fen Edebiyat Fak. Matematik Böl.,Çiftlikköy kampüsü, Mersin.
}

Geliş Tarihi (Received Date): 04.05.2021

Kabul Tarihi (Accepted Date): 05.07.2021

\section{$\ddot{\mathbf{O z}}$}

Bu çalışmada soft expert kümelere dayanan farklı bir tip çok kriterli karar verme metodu prostat kanser teşhişi için önerildi. Biyopsinin gerekliliğini belirleyen ve prostat kanser risk oranını veren bu metod, diğer metotlardan [1, 2, 3] elde edilen sonuçlarla karşılaştırma yapmak için verildi. Sonuç olarak biyopsi yapılan hastaların sayısı azaltıldi.

Anahtar kelimeler: Soft expert küme, soft küme, çok kriterli karar verme yöntemleri, prostat kanseri.

\section{An application of decision making problem based on soft expert sets for diagnosing prostate cancer}

\begin{abstract}
In this study, a different type of multicriteria decision making method based on soft expert sets is proposed for diagnosing prostate cancer. This method which determines the necessity of biopsy and gives a risk range of prostate cancer is given for comparing results have been obtained from other methods [1, 2, 3]. Consequently, the number of patients that are biopsied is reduced.
\end{abstract}

Keywords: Soft expert set, soft set, multicriteria decision making methods, prostate cancer.

"Zehra GÜZEL ERGÜL, zguzel@ahievran.edu.tr, http://orcid.org/0000-0001-5717-1626

Naime DEMIRTAŞ, naimedemirtas@mersin.edu.tr, http://orcid.org/0000-0003-4137-4810 


\section{Giriş}

Yaşamımızın herhangi bir anında veya bilimsel çalışmalarda içerisinde belirsizliğin bulunduğu problemlerle karşılaşırız. Bu tür belirsizliklerin bilimsellik ifade etmesi için matematiksel olarak modellenmesine ihtiyaç duyulmaktadır. $\mathrm{Bu}$ yüzden bazı araştırmacılar tarafından fuzzy (bulanık) küme teori [4], rough (kaba) küme teori [5], soft (esnek) küme teori [6] ve soft expert (uzman) küme teori [7] gibi birkaç model önerilmiştir.

Belirsizlik için verilen bu küme teorileri kullanılarak bazı araştırmacılar tarafından mühendislik, ekonomi ve tıp gibi alanlarda karşılaşılan problemlerin çözümlenmesinde çok kullanışlı matematiksel bir araç olan karar verme metotları incelenmiştir. Karar verme, yaşamımızda sık karşılaştığımız bir olaydır. Bu yüzden belirsizlik içeren problemler için karar verme metotları üzerine birçok çalışma yapılmıştır. Bunlardan bazıları olarak $[8,9,10,11,12,13,14]$ siralanabilir.

Biz bu çalışmada ise tıp alanında prostat kanseri şüphesiyle doktora başvuran hastalara biyopsi uygulanıp uygulanmaması kararını belirleyecek ve doktorlara kanser riskinin sıralamasını verecek olan en uygun metodu araştırdık. Çünkü prostat kanseri sanayileşmiş ülkelerde erkeklerde ölüme sebep olan en yaygın ikinci kanser türüdür. Bu yüzden prostat kanserinin teşhisi ve sonucunun tahmini hakkında yapılan birçok çalışma vardır. Örneğin; Saritas vd. [15] hastanın yaş, PV (prostat hacmi) ve PSA (prostat spesifik antijen) verilerinin kullanıldığı kural tabanlı fuzzy uzman sistemi (FES) geliştirmişlerdir. Benecchi [16], hastaların PSA, fPSA (serbest prostat spesifik antijen) ve yaş verilerini kullanarak neuro-fuzzy sistemi geliştirmiştir. Keleş vd. [17] prostat kanserinin teşhisinde kullanılan neuro-fuzzy sınıflandırıcıyı yapmışlardır. Saritas vd. [18] hastaların PSA, fPSA ve yaş verilerini kullanarak kanser olup olmadıklarının tahminini sağlayacak yapay sinirsel (neural) ağı geliştirmişlerdir. Yüksel vd. [19] hastaların PSA, PV ve yaş faktörlerini kullanarak, fuzzy ve soft kümelere dayalı soft uzman sistemi (SES) olarak adlandırılan bir tahmin sistemi oluşturmuşlardır. Yüksel vd. [1], Feng'in soft küme tabanlı grup karar verme metodunda [20] soft örtü yaklaşımları kullanmış ve prostat kanser riski olan hastalara biyopsi uygulanıp uygulanmaması açısından en uygun seçimi elde etmeyi amaçlayan, tıp alanında bir örnek sunmuşlardır. Tozlu vd. [3] prostat kanser riskini hesaplamak için Yüksel vd.' nin çalışmasındaki [2] tıp problemine fuzzy TOPSİS metodunu [21] uygulamış ve diğer metottan elde edilen sonuçlar ile karşılaştırmıştır.

Biz bu çalışmada, bir çok kriterli grup karar verme metodunda soft kümeleri ve soft expert kümeleri kullanıp bir tahmin sistemi oluşturduk. Bu tahmin sisteminde, tek bir karar verici yerine uzman bir grup bulunduğundan soft expert kümelerin karar verme problemlerinde daha ideal sonuçlar verdiğini gösterdik. Bazı parametrelerden faydalanarak uzman doktora, prostat kanser riskini hesaplaması konusunda; daha objektif bir sıralama ve en uygun seçimi belirleyerek yardımcı olmayı hedefledik.

Prostat kanserinin kesin teşhisi ancak biyopsi ile mümkündür. Biyopsi işleminin bazı zorlukları vardır, hastada bazı zararlara neden olabilir ve maliyeti yüksektir. Bu yüzden hastalara biyopsi işlemini uygulamak doktorlar için önemli bir karardır ve düşük risk altındaki hastalara uygulamaktan kaçınılmalıdır. 
Sonuç olarak tıp alanında prostat kanseri şüphesiyle doktora başvuran hastaların biyopsi gerekliliğini inceleyen ve doktorlara kanser riskinin sıralamasını veren bu metod ile uzman doktorlar, prostat kanser riski olan hastalara biyopsi uygulanıp uygulanmamasi kararını belirleyecektir. Dolayısıyla gerekli olmayan biyopsi işlemlerinin yapılması engellenmiş olur.

\section{Materyal ve metod}

$\mathrm{Bu}$ çalışmada prostat kanser riskini hesaplamak için, gerçek hayatta belirsizliğin bulunduğu problemlerin çözülmesine yardımcı olmak üzere, araştırmacılar tarafindan önerilen küme teorilerinden soft kümeler ve soft expert kümeler kullanılmaya uygun görülmüştür. Ayrıca literatürdeki çok kriterli karar verme metotları incelenmiş, incelenen bu metotlardan daha objektif bir sıralama ve en uygun seçimi veren belirlenmiştir. Daha sonra yapılan araştırmalar doğrultusunda belirlenen bu çok kriterli karar verme metodunda soft kümeler ve soft expert kümelerden faydalanılarak tıp alanında bir tahmin sistemi tasarlanmıştır. Prostat kanserinin teşhisi için tasarladığımız bu sistemde kullandığımız veriler Necmettin Erbakan Üniversitesi, Meram Tıp Fakültesi, Üroloji bölümünden (Prof. Dr. Ünal SERT) alınmıştır. Veri kümesi 78 hastanın PSA, fPSA, PV ve yaş değerlerinden oluşmaktadır [1, 2, 3]. Tasarladığımız sistemde giriş değerleri olarak PSA, fPSA, PV ve yaş kullanılarak, çıkış değeri olarak prostat kanser riskinin yüzdesi elde edilmiştir.

$\mathrm{Bu}$ çalışmada kullanılan soft kümeler ve soft expert kümelerin temel tanımlarını hatırlayalım. Bu kavramlarla ilgili daha fazla detay için [6, 7, 22, 23, 24]'teki makaleler incelenebilir.

Tanım 1: [6] $U$ bir evrensel küme ve $E$ parametrelerin kümesi olsun. $P(U), U$ 'nun kuvvet kümesini göstersin. $A \subseteq E$ ve $F: A \rightarrow P(U)$ küme değerli bir dönüşüm olmak üzere $G=(F, A)$ çifti, $U$ üzerinde bir soft küme olarak adlandırılır.

Diğer bir deyişle $U$ evrensel kümesi üzerindeki bir soft küme, $U$ kümesinin alt kümelerinin parametrelenmiş bir ailesidir. Her $\varepsilon \in A$ için $F(\varepsilon), G=(F, A)$ soft kümesinin $\varepsilon$-yaklaşık elemanlarının kümesi olarak düşünülebilir. Dikkat edelim ki, $F(\varepsilon)$ keyfi olabilir. Bunlardan bazıları boş ve bazıları boştan farklı kesişime sahip olabilir.

Şimdi, soft expert küme kavramını hatırlayalım.

Tanım 2: [7] $U$ bir evrensel küme, $E$ parametrelerin kümesi ve $X$ uzmanların kümesi olsun. $O$ fikirlerin kümesi, $Z=E \times X \times O$ ve $A \subset Z$ olsun. $P(U)$, $U$ 'nun kuvvet kümesi ve $F: A \rightarrow P(U)$ küme değerli bir dönüşüm olmak üzere $(F, A)$ çifti, $U$ üzerinde soft expert küme olarak adlandırılır.

$\mathrm{Bu}$ makalede $O=\{0=$ katılmıyorum, $1=$ katılıyorum $\}$ şeklinde $O$ kümesinde sadece iki-değerli fikir olduğunu varsayarız. Fakat çok değerli fikirler de varsayılabilir. 


\section{Uygulama}

Bu çalışma, Necmettin Erbakan Üniversitesi Meram Tıp Fakültesine prostat şikayeti ile gelen 78 hasta ile ilgilidir. Prostat kanseri çoğu ülkede erkekler arasında en sık görülen ikinci kanser türüdür. Bilinir ki prostat kanseri erken teşhis edildiğinde hasta tamamen tedavi edilebilir. Prostat kanserinin kesin teşhisi biyopsi ile mümkündür. Fakat biyopsi yöntemi riskli olduğundan uygulanması istenmez. Çünkü teşhis için biyopsi yapılırsa kanser diğer hayati organlara yayılabilir $[18,25,26]$. Bu sebeple biz çalışmamızda uzman doktorlar için prostat kanser riski olan hastalara, biyopsi uygulanıp uygulanmaması kararını belirlemeye yardımcı olacak, bir tahmin sistemi geliştirdik. Bu sistem kullanıcıya kanser riski oranını verir. Uzman doktorlar soft kümeler ve soft expert kümelere dayalı bu çok kriterli karar verme metodunu kullanarak prostat şikâyetiyle gelen herhangi bir hastanın biyopsisinin gerekli olup olmadığı hakkında karar analizi yapabilir. Böylece doktorlar, hastada bazı fiziksel zararlara neden olabilen bir uygulama olan biyopsi işlemini gereksiz yere yapmaktan kaçınmış olacaktır.

$\mathrm{Bu}$ süreçte laboratuvar verisi olarak hastaların PSA, fPSA, PV ve yaş değerlerini kullanırız. Çünkü doktorlar prostat şikayeti olan hastaları öncelikle onların PSA, fPSA, PV ve yaş değerleri ile kontrol ederler. Bu nedenle biz aşağıdaki metotta her hastanın prostat kanser riskini; PSA, fPSA, PV ve yaş değerleri ile üretilen soft expert küme ile ifade ederiz.

Şimdi her hastanın prostat kanser riskini belirten soft expert kümeyi üretelim. Soft expert kümeyi elde etmek için ilk olarak Tanım 2'de bahsedilen $U$ evrensel kümesine, parametrelerin $E$ kümesine, uzmanların $X$ kümesine ve fikirlerin $O$ kümesine ihtiyaç duyarız. Sırasıyla bu kümeleri açıklayalım.

Adım 1: $U=\left\{u_{k}: u_{1}=1, u_{2}=2, u_{3}=3, \ldots, u_{78}=78, k=1,2,3, \ldots, 78\right\}$, Necmettin Erbakan Üniversitesi Meram T1p Fakültesine prostat şikayetiyle gelen hastaların oluşturduğu evrensel küme olsun.

Adım 2: Prostat kanseri; ailenin kanser geçmişi, kandaki PSA miktarı, kandaki fPSA miktarı, prostat hacmi ve yaş gibi çeşitli faktörlere dayanır. Prostat kanserli hastaların ilk teşhisi için PSA, fPSA, PV ve yaş çok önemli faktörlerdir. Bu yüzden biz bunları parametrelerin kümesi olarak ifade ederiz. Yani $E=\left\{e_{1}=P S A, e_{2}=f P S A, e_{3}=\right.$ $\left.P V, e_{4}=Y a s ̧\right\}$ parametre kümesi olsun.

Adım 3: Varsayalım ki $X=\left\{X_{d_{1}}, X_{d_{2}}, X_{d_{3}}\right\}, U$ kümesindeki hastaları değerlendirmek için prostat kanseri alanında uzmanların oluşturduğu, uzman doktor grubu olsun. Uzman doktor grubundaki her doktor, hastaları PSA, fPSA, PV ve yaş parametrelerine göre değerlendirir. Her doktorun değerlendirmesinin aynı öneme sahip olduğunu varsayarı.

Adım 4: Bu çalışmanın en önemli adımı, soft expert kümeleri üretmek için gerekli olan fikirlerin kümesidir. Bu çalışmada $O$ kümesinde sadece iki-değerli fikirleri varsayarız yani $O=\{0=$ katılmıyorum, $1=$ katılıyorum $\}$. Prostat kanseri şüphesi bulunan hastalar $1=$ katılıyorum ve diğerleri $0=$ katılmıyorum ile gösterilir.

Şimdi problemimizi çözmeye başlayalım. 
Adım 5: Prostat kanseri şüphesiyle doktora başvuran 78 hastanın, veri kümesindeki değerler, soft küme gösterimine uygun değildir. Bu yüzden uzman doktorlar yardımıyla soft kümeyi tanımlarken, prostat kanseri şüphesiyle doktora başvuran 78 hastayı, evrensel küme olarak ve $E=\left\{e_{1}=P S A, e_{2}=f P S A, e_{3}=P V, e_{4}=Y a s ̧\right\}$ parametre kümesi olarak kullanırız. Çünkü daha önce belirttiğimiz gibi, doktorlar prostat şikayeti ile gelen hastaları ilk olarak PSA, fPSA, PV ve yaş parametrelerine göre değerlendirir. $\mathrm{Bu}$ parametrelerin detayları aşağıda listelenmiştir:

$\boldsymbol{e}_{\mathbf{1}}$ için; Kandaki PSA miktarı 50 ve üzeri

$\boldsymbol{e}_{2}$ için; Kandaki fPSA miktarı 12 ve üzeri

$\boldsymbol{e}_{3}$ için; PV değeri 20 ve üzeri

$\boldsymbol{e}_{4}$ için; Yaş 54 ve üzeri

Belirlenen parametrelere bağlı olarak, bu verileri soft kümeler olarak formülleştirip, $U$ üzerinde $G=(F, E)$ soft kümesini üretiriz. Yani $U=\left\{u_{k}: u_{1}=1, u_{2}=2, u_{3}=\right.$ $\left.3, \ldots, u_{78}=78\right\}$ kümesi, 78 hastadan oluşan evrensel kümesi ve $E=\left\{e_{1}=P S A, e_{2}=\right.$ fPSA, $\left.e_{3}=P V, e_{4}=Y a s ̧\right\}$ parametre kümesi,

$F(P S A), 50$ ve 50 den büyük değere sahip olan hastaları

$F(f P S A), 12$ ve 12 den büyük değere sahip olan hastaları

$F(P V), 20$ ve 20 den büyük değere sahip olan hastaları

$F(Y a s ̧), 54$ ve 54 den büyük değere sahip olan hastaları

göstermek üzere uzman doktor yardımıyla $G=(F, E)$ soft kümesini aşağıdaki şekilde tanımlarız.

$F(P S A)=\{1,4,6,7,9,11,13,15,16,18,19,20,22,23,25,26,28,29,31,33,34,36$

$37,39,40,42,43,45,46,47,48,49,52,53,55,56,58,60,62,63,64,66,68,70,71,72$,

$73,74,75,77\}$

$F(f P S A)=\{1,4,7,8,9,10,11,13,15,16,17,18,19,20,22,23,24,25,26,28,29$,

$31,32,33,34,35,36,37,39,40,42,43,45,46,48,49,51,52,53,55,56,58,60,62,63$,

$64,66,68,70,71,72,73,74,75,76,77,78\}$

$F(P V)=U$

$F(Y a s ̧)=\{1, \ldots, 29,31, \ldots, 56,58,60, \ldots, 78\}$

Adım 6: $G=(F, E)$ soft kümesi, doktorların ortak fikre sahip oldukları, ilk başlangıç verilerinin bir analizidir. Bu ilk başlangıç verilerine dayanarak her bir uzman doktor, hastalıktan şüphelenilen ama henüz kesin tanı konulmamış hastaların, her bir parametreye göre bir ön değerlendirmesini yapar. Bu ön değerlendirme bize soft expert kümemizi verir. Şimdi, katılıyorum - soft expert kümesini verelim. Burada örneğin; 
$F\left(P S A, X_{d_{1}}, 1\right)$ ifadesi $X_{d_{1}}$ doktoruna göre, PSA parametresine bağlı prostat kanseri şüphesi taşıyan ve biyopsi yapılması gereken hastaları gösterir.

$$
\begin{aligned}
& F\left(P S A, X_{d_{1}}, 1\right) \\
& =\{1,4,6,7,9,11,13,15,16,18,19,20,22,23,25,26,28,29,31,33,34,36
\end{aligned}
$$

$37,39,40,42,43,45,46,47,48,49,52,53,55,56,58,60,62,63,64,66,68,70,71,72$

$$
\begin{aligned}
& \quad 73,74,75,77\} \\
& F\left(P S A, X_{d_{2}}, 1\right) \\
& =\{1,4,6,7,9,11,13,15,16,18,20,22,23,25,26,28,29,31,33,34,36,37,
\end{aligned}
$$

$39,40,42,43,45,46,47,48,49,52,53,55,56,58,60,62,64,66,68,70,72,73,74,75,77\}$

$$
F\left(P S A, X_{d_{3}}, 1\right)
$$$$
=\{1,4,6,7,9,11,13,15,16,18,19,20,22,23,25,26,28,29,31,33,34,36 \text {, }
$$

$37,39,40,42,43,45,46,47,48,49,52,53,55,56,58,60,62,64,66,68,70,72,73,75,77\}$

$$
\begin{aligned}
& F\left(f P S A, X_{d_{1}}, 1\right) \\
& =\{1,4,7,8,9,11,13,15,16,17,18,19,20,22,23,25,26,28,29,31,33,
\end{aligned}
$$

$34,36,37,39,40,42,43,45,46,48,49,51,52,53,55,56,58,60,62,63,64,66,68,70$,

$$
\begin{aligned}
& 71,72,73,74,75,77\} \\
& F\left(f P S A, X_{d_{2}}, 1\right) \\
& =\{1,4,7,9,11,13,15,16,18,20,22,23,24,25,26,28,29,31,33,34,36,
\end{aligned}
$$

$37,39,40,42,43,45,46,48,49,51,52,53,55,56,58,60,62,64,66,68,70,72,73,74$,

$75,77,78\}$

$$
\begin{aligned}
& F\left(f P S A, X_{d_{3}}, 1\right) \\
& =\{1,4,7,9,11,13,15,16,18,19,20,22,23,25,26,28,29,31,33,34,36,
\end{aligned}
$$

$37,39,40,42,43,45,46,48,49,51,52,53,55,56,58,60,62,64,66,68,70,72,73,75$, $76,77,78\}$ 
$F\left(P V, X_{d_{1}}, 1\right)$

$=\{1,4,6,7,8,9,11,13,15,16,17,18,19,20,22,23,25,26,28,29,31,33$,

$34,36,37,39,40,42,43,45,46,47,48,49,51,52,53,55,56,58,60,62,63,64,66,68$, $70,71,72,73,74,75,77\}$

$F\left(P V, X_{d_{2}}, 1\right)$

$=\{1,2,3,4,6,7,9,11,13,15,16,18,20,22,23,24,25,26,28,29,31,33,34$,

$36,37,39,40,41,42,43,45,46,47,48,49,51,52,53,55,56,58,60,62,64,66,68,70$, $72,73,74,75,77,78\}$

$F\left(P V, X_{d_{3}}, 1\right)$

$=\{1,2,4,6,7,9,11,13,15,16,18,19,20,22,23,25,26,28,29,31,33,34$,

$36,37,39,40,41,42,43,45,46,47,48,49,51,52,53,54,55,56,58,60,62,64,66,67$, $60,70,72,73,75,76,77,78\}$

$F\left(Y_{\text {aş, }} X_{d_{1}}, 1\right)$

$=\{1,4,6,7,8,9,11,13,15,16,17,18,19,20,22,23,25,26,28,29,31,33$,

$34,36,37,39,40,42,43,45,46,47,48,49,51,52,53,55,56,58,60,62,63,64,66,68$, $70,71,72,73,74,75,77\}$

$F\left(\right.$ Yaş, $\left.X_{d_{2}}, 1\right)$

$=\{1,2,3,4,6,7,9,11,13,15,16,18,20,22,23,24,25,26,28,29,31,33,34$,

$36,37,39,40,41,42,43,45,46,47,48,49,51,52,53,55,56,58,60,62,64,66,68,70$, $72,73,74,75,77,78\}$

$F\left(\right.$ Yaș, $\left.X_{d_{3}}, 1\right)$

$=\{1,2,4,6,7,9,11,13,15,16,18,19,20,22,23,25,26,28,29,31,33,34$,

$36,37,39,40,41,42,43,45,46,47,48,49,51,52,53,54,55,56,58,60,62,64,66,67$, $68,70,72,73,75,76,77,78\}$ 
Katıliyorum - soft expert kümesinin tümleyeni, katılmıyorum - soft expert kümesi olarak adlandırılır öyle ki katılıyorum - soft expert kümesinin hastalarının kalanından elde edilir. Bu nedenle, katılmıyorum - soft expert kümesini detaylı olarak listelemeye ihtiyaç yoktur.

Adım 7: Prostat kanser riski olan hastalara biyopsi uygulanması için en uygun seçimi elde etmede aşağıdaki algoritmayı [7] kullanırız.

(i) Soft expert kümenin orijinal ifadesini gir.

(ii) Katılıyorum - soft expert kümesini göstermek için

dönüşümünü kullan.

$$
u_{i j}= \begin{cases}1, & u_{i} \in F_{1}(e) \\ 0, & u_{i} \notin F_{1}(e)\end{cases}
$$

Katılmıyorum - soft expert kümesini göstermek için

dönüşümünü kullan.

$$
u_{i j}= \begin{cases}1, & u_{i} \in F_{0}(e) \\ 0, & u_{i} \notin F_{0}(e)\end{cases}
$$

(iii) Katılıyorum - soft expert kümesi için $c_{j}=\sum_{i} u_{i j}$ bul.

(iv) Katılmıyorum - soft expert kümesi için $k_{j}=\sum_{i} u_{i j}$ bul.

(v) $s_{j}=c_{j}-k_{j}$ bul.

(vi) $s_{m}=\max _{j}$ olacak şekildeki $m$ 'yi bul. Bu durumda $s_{m}$, en büyük değeri verdiği için, yüksek kanser riskli hastayı belirlemek için en iyi alternatif olarak kullanilır.

Sonuç olarak biz 78 hasta için, yukarıdaki algoritmanın (v). adımında elde ettiğimiz $s_{j}$ değerlerini sıralarız. Örneğin $u_{1}, u_{21}, u_{41}, u_{51}$ hastaları için bu işlem aşağıdaki şekildedir.

Tablo 1. Katılıyorum - soft expert kümesinin tablo üzerinde gösterimi

\begin{tabular}{|c|c|c|c|c|}
\hline $\boldsymbol{U}$ & $\boldsymbol{u}_{\mathbf{1}}$ & $\boldsymbol{u}_{\mathbf{2 1}}$ & $\boldsymbol{u}_{\mathbf{4 1}}$ & $\boldsymbol{u}_{\mathbf{5 1}}$ \\
\hline$\left(e_{1}=P S A, X_{d_{1}}\right)$ & 1 & 0 & 0 & 0 \\
\hline$\left(e_{2}=f P S A, X_{d_{1}}\right)$ & 1 & 0 & 0 & 1 \\
\hline$\left(e_{3}=P V, X_{d_{1}}\right)$ & 1 & 0 & 0 & 1 \\
\hline$\left(e_{4}=Y a s ̧, X_{d_{1}}\right)$ & 1 & 0 & 0 & 1 \\
\hline$\left(e_{1}=P S A, X_{d_{2}}\right)$ & 1 & 0 & 0 & 0 \\
\hline$\left(e_{2}=f P S A, X_{d_{2}}\right)$ & 1 & 0 & 0 & 1 \\
\hline$\left(e_{3}=P V, X_{d_{2}}\right)$ & 1 & 0 & 1 & 1 \\
\hline$\left(e_{4}=Y a s ̧, X_{d_{2}}\right)$ & 1 & 0 & 1 & 1 \\
\hline$\left(e_{1}=P S A, X_{d_{3}}\right)$ & 1 & 0 & 0 & 0 \\
\hline$\left(e_{2}=f P S A, X_{d_{3}}\right)$ & 1 & 0 & 0 & 1 \\
\hline
\end{tabular}


Tablo 1. (devam1).

\begin{tabular}{|c|c|c|c|c|}
\hline$\left(e_{3}=P V, X_{d_{3}}\right)$ & 1 & 0 & 1 & 1 \\
\hline$\left(e_{4}=Y a s ̧, X_{d_{3}}\right)$ & 1 & 0 & 1 & 1 \\
\hline$c_{j}=\sum_{i} u_{i j}$ & $c_{1}=12$ & $c_{21}=0$ & $c_{41}=4$ & $c_{51}=9$ \\
\hline
\end{tabular}

Tablo 2. Katılmıyorum - soft expert kümesinin tablo üzerinde gösterimi

\begin{tabular}{|c|c|c|c|c|}
\hline $\boldsymbol{U}$ & $\boldsymbol{u}_{\mathbf{1}}$ & $\boldsymbol{u}_{\mathbf{2 1}}$ & $\boldsymbol{u}_{\mathbf{4 1}}$ & $\boldsymbol{u}_{\mathbf{5 1}}$ \\
\hline$\left(e_{1}=P S A, X_{d_{1}}\right)$ & 0 & 1 & 1 & 1 \\
\hline$\left(e_{2}=f P S A, X_{d_{1}}\right)$ & 0 & 1 & 1 & 0 \\
\hline$\left(e_{3}=P V, X_{d_{1}}\right)$ & 0 & 1 & 1 & 0 \\
\hline$\left(e_{4}=Y a s ̧, X_{d_{1}}\right)$ & 0 & 1 & 1 & 0 \\
\hline$\left(e_{1}=P S A, X_{d_{2}}\right)$ & 0 & 1 & 1 & 1 \\
\hline$\left(e_{2}=f P S A, X_{d_{2}}\right)$ & 0 & 1 & 1 & 0 \\
\hline$\left(e_{3}=P V, X_{d_{2}}\right)$ & 0 & 1 & 0 & 0 \\
\hline$\left(e_{4}=Y a s ̧, X_{d_{2}}\right)$ & 0 & 1 & 0 & 0 \\
\hline$\left(e_{1}=P S A, X_{d_{3}}\right)$ & 0 & 1 & 1 & 1 \\
\hline$\left(e_{2}=f P S A, X_{d_{3}}\right)$ & 0 & 1 & 1 & 0 \\
\hline$\left(e_{3}=P V, X_{d_{3}}\right)$ & 0 & 1 & 0 & 0 \\
\hline$\left(e_{4}=Y a s ̧, X_{d_{3}}\right)$ & 0 & 1 & 0 & 0 \\
\hline$k_{j}=\sum u_{i j}$ & $k_{1}=0$ & $k_{21}=12$ & $k_{41}=8$ & $k_{51}=3$ \\
\hline$i$ & & & & \\
\hline
\end{tabular}

Tablo 3. $s_{j}$ değerinin tablo üzerinde gösterimi

\begin{tabular}{|c|c|c|c|}
\hline $\boldsymbol{U}$ & $\boldsymbol{s}_{\boldsymbol{j}}=\boldsymbol{c}_{\boldsymbol{j}}-\boldsymbol{k}_{\boldsymbol{j}}$ & $\boldsymbol{c}_{\boldsymbol{j}}=\sum_{\boldsymbol{i}} \boldsymbol{u}_{\boldsymbol{i} \boldsymbol{j}}$ & $\boldsymbol{k}_{\boldsymbol{j}}=\sum_{\boldsymbol{i}} \boldsymbol{u}_{\boldsymbol{i} \boldsymbol{j}}$ \\
\hline$u_{1}$ & 12 & 12 & 0 \\
\hline$u_{21}$ & -12 & 0 & 12 \\
\hline$u_{41}$ & -4 & 4 & 8 \\
\hline$u_{51}$ & 6 & 9 & 3 \\
\hline
\end{tabular}


$\mathrm{Bu}$ işlemi 78 hasta için tekrarlarız. Böylece her hasta için $\{12,6,4,0,-4,-6,-8,-12\}$ gibi değerlendirme değerlerinin kümesini elde ederiz. Elde ettiğimiz değerleri sıralarız ve en büyük değerlendirme değerine dayanarak en yüksek derece kanser riski taşıyan hastaları, en küçük değerlendirme değerine dayanarak da en düşük derece kanser riski taşıyan hastaları belirleriz. Bu değerleri kullanarak ve uzman doktorların önerileri ışığında aşağıdaki sonuçları elde ederiz:

$$
\begin{aligned}
& u_{1} \approx u_{4} \approx u_{7} \approx u_{9} \approx u_{11} \approx u_{13} \approx u_{15} \approx u_{16} \approx u_{18} \approx u_{20} \approx u_{22} \approx u_{23} \approx u_{25} \approx u_{26} \\
& \approx u_{28} \approx u_{29} \approx u_{31} \approx u_{33} \approx u_{34} \approx u_{36} \approx u_{37} \approx u_{39} \approx u_{40} \approx u_{42} \approx u_{43} \approx u_{45} \approx u_{46} \\
& \approx u_{48} \approx u_{49} \approx u_{52} \approx u_{53} \approx u_{55} \approx u_{56} \approx u_{58} \approx u_{60} \approx u_{62} \approx u_{64} \approx u_{66} \approx u_{68} \approx u_{70} \\
& \approx u_{72} \approx u_{73} \approx u_{75} \approx u_{77}=12>u_{6} \approx u_{47} \approx u_{51}=\mathbf{6}>u_{19} \approx u_{74}=4>u_{78}=\mathbf{0} \\
& >u_{2} \approx u_{41} \approx u_{63} \approx u_{71}=-4>u_{8} \approx u_{17} \approx u_{24} \approx u_{76}=-6>u_{3} \approx u_{54} \approx u_{67}= \\
& -8>u_{5} \approx u_{10} \approx u_{12} \approx u_{14} \approx u_{21} \approx u_{27} \approx u_{30} \approx u_{32} \approx u_{35} \approx u_{38} \approx u_{44} \approx u_{50} \approx \\
& u_{57} \approx u_{59} \approx u_{61} \approx u_{65} \approx u_{69}=-12
\end{aligned}
$$

12 en yüksek değerdir ve 44 hasta bu değere sahiptir. Bu yüzden onlar yüksek kanser riski altındadır ve kesinlikle biyopsiye ihtiyaç duyarlar.

$>\quad 6$ değerine sahip 3 hasta ve 4 değerine sahip 2 hasta da kısmen risk altındadır ve doktor gözetiminde olmalıdırlar.

$>\quad$ Diğer hastalar düşük risk altındadır ve biyopsiye ihtiyaç duymazlar.

Necmettin Erbakan Üniversitesi, Meram Tıp Fakültesi verilerine göre 78 hastanın tamamına biyopsi uygulanmıştır ve bunlardan sadece 44'üne kanser teşhisi konmuştur. Yani geriye kalan 34 hastaya gereksiz yere biyopsi yapılmıştır. Bizim çalışmamıza göre, eğer hastalara ait veriler ilk anda bu tahmin sistemi ile değerlendirilmiş olsaydı düşük risk grubunda yer alan 29 hastaya yapılması gereksiz olan biyopsi uygulanmasından kaçınılmış olacaktı. Böylece biyopsi uygulanan hasta sayısını azaltmış oluruz.

Biyopsi gerekliliğini belirlediğimiz bu metottan elde ettiğimiz sonuçlarla, diğer metotlardan [1, 2, 3] elde edilen sonuçları karşılaştırırsak; [1, 2, 3] da yüksek kanser riski altında olan 46 hasta belirlenmiştir. Bu çalışmada ise yüksek kanser riski altında olan 44 hasta belirlenmiştir. Dolayısıyla biyopsi yapılması gereken hasta sayısı, diğer çalışmalardaki hasta sayılarından daha az sayıya düşürülmüştür. $\mathrm{Bu}$ sonuç bize bu metodun, [1, 2, 3] daki metotlardan daha iyi sonuçlar verdiğini gösterir. Bu uygulama, herhangi bir işlem olmaksızın tüm uzmanların fikrini bilmemize ve en uygun nesneyi seçmemize imkan sağlar. Bu çalışmada çok önemli bir karar, sadece tek bir karar verici yerine bir uzman grup tarafindan alınır ve ayrıca kullanılan bu method ile hastalık teşhisinde daha gerçekçi kurallar elde edilir. 


\section{Sonuç}

Bu çalışmada, son yıllarda erkeklerde sıkça görülen prostat kanserinin teşhisi için bazı parametrelerden faydalanarak elde edilmiş, hızlı, ekonomik ve geleneksel tanı sistemlerinden daha risksiz olan bir tahmin sistemi oluşturduk. Bu tahmin sistemi sayesinde uzman doktora prostat şikâyetiyle gelen bir hastanın PSA, fPSA, PV ve yaş verileri yardımıyla prostat kanseri olma riskinin yüzdesi hesaplanmıştır. Hesaplanan bu değerle uzman doktor, prostat şikâyetiyle gelen herhangi bir hastanın, biyopsi işlemine ilişkin karar verebilir ve böylece maliyeti yüksek olan, hastada bazı fiziksel zararlara neden olabilen, yapılması gerekli olmayan biyopsi işlemlerinin önüne geçilmiş olur.

$\mathrm{Bu}$ çalışma ile, soft kümeler ve soft expert kümelerin çok kriterli karar verme metotlarında kullanılması açısından çalışma alanlarının zenginleştirilmesi ve geliştirilmesi sağlanmış olacaktır. Ayrıca bu çalışma, elde edilen bulgulardan dolayı yapılması muhtemel diğer çalışmalara kaynak oluşturacaktır.

Prof. Dr. I. Ünal Sert'e, Necmettin Erbakan Üniversitesi Meram Tip Fakültesi Üroloji Bölümü'ndeki bu veri kümesini bizimle paylaştığı için minnetlerimizi sunarız.

\section{Teșekkür}

Bu çalışma Kırşehir Ahi Evran Üniversitesi Bilimsel Araştırma Projeleri Koordinasyon birimi tarafından FEF A4.18.024 proje numarası ile desteklenmiştir.

\section{Kaynaklar}

[1] Güzel Ergül, Z. and Yüksel, Ş., A new type of soft covering based rough sets applied to multicriteria group decision making for medical diagnosis, Mathematical Sciences and Applications E-Notes, 7 (1): 28-38, (2019).

[2] Yüksel, Ş., Güzel Ergül, Z. and Tozlu, N., Soft covering based rough sets and their application, The Scientific World Journal, Article ID 970893: 9 pages, http:Ildx.doi:10.1155/2014/970893, (2014).

[3] Tozlu, N., Dizman (Simsekler), T., Davvaz, B. and Yuksel, S., A comparative study for medical diagnosis of prostate cancer, New Trends in Mathematical Sciences, 7 (1): 102-112, (2019).

[4] Zadeh, L.A., Fuzzy sets, Inf. Control, 8: 338-353, (1965).

[5] Pawlak, Z., Rough sets, Int. J. Comput. Inf. Sci., 11: 341-356, (1982).

[6] Molodtsov, D., Soft set theory-first results, Computers and Mathematics with Applications, 37: 19-31, (1999).

[7] Alkhazaleh S. and Razak Salleh S., Soft expert sets, Advances in Decision Sciences, Article ID 757868: 12 pages, doi:10.1155/2011/757868, (2011).

[8] Hassan, N., Uluçay, V. and Şahin, M., Q-Neutrosophic soft expert set and its application in decision making, International Journal of Fuzzy System Applications, 7 (4) : 37- 61, (2018).

[9] Demir, İ., N-soft mappings with application in medical diagnosis, Mathematical Methods in the Applied Sciences, 44 (8): 7343-7358, (2021).

[10] Özgür, N.Y. and Taş, N., A note on application of fuzzy soft sets to investment decision making problem, Journal of New Theory, 1(7): 1-10, (2015). 
[11] Kalaichelvi, Dr. A. and Malini, P.H., Application of fuzzy soft sets to investment decision making problem, International Journal of Mathematical Sciences and Applications, 1 (3): 1583-1586, (2011).

[12] Taş, N., Özgür, N.Y. and Demir, P., An application of soft set and fuzzy soft set theories stock management., Süleyman Demirel University Journal of Natural and Applied Sciences, 21 (3): 791-796, (2017).

[13] Karaca, F. and Taş, N., Decision making problem for Life and Non-Life insurances, Journal of Balıkesir University Institute of Science and Technology, 20 (1): 572-588, (2018).

[14] Irkin, R., Özgür, N. Y. and Taş, N., Optimization of lactic acid bacteria viability using fuzzy soft set modelling, An International Journal of Optimization and Control: Theories \& Applications, 8 (2): 266-275, (2018).

[15] Saritas, I., Allahverdi, N. and Sert, U., A fuzzy expert system design for diagnosis of prostate cancer, International Conference on Computer Systems and Technologies-CompSysTech 2003, Sofia, Bulgaria, s. 345-351, 19-20, (2003).

[16] Benecchi, L., Neuro-fuzzy system for prostate cancer diagnosis, Urology, 68 (2): 357-361, (2006).

[17] Keles, A., Hasiloglu, A.S., Keles, A. and Aksoy, Y., Neuro-fuzzy classification of prostate cancer using NEFCLASS-J, Computers in Biology and Medicine, 37: 1617-1628, (2007).

[18] Saritas, I., Ozkan, I.A. and Sert, U., Prognasis of prostate cancer by artficial neural networks, Expert Systems with Applications, 37: 6646-6650, (2010).

[19] Yuksel, S., Dizman, T., Y1ldizdan, G. and Sert, U., Application of soft sets to diagnose the prostate cancer risk, J. Inequal. Appl., 229, (2013).

[20] Feng, F., Soft rough sets applied to multicriteria group decision making, Annals of Fuzzy Mathematics and Informatics, 2 (1): 69-80, (2011).

[21] Chen-Tung C. Extensions of the TOPSIS for group decision-making under fuzzy environment, Fuzzy Sets and Systems, 114: 1-9, (2000).

[22] Molodtsov, D., The theory of soft sets, URSS Publishers, Moscow, (2004).

[23] Chen, D., Tsang, E.C.C., Yeung, D.S. and Wang, X., The parameterization reduction of soft sets and its applications, Computers and Mathematics with Applications, 49: 757-763, (2005).

[24] Feng, F., Li, C., Davvaz, B. and Ali, M.I., Soft sets combined with fuzzy sets and rough sets: a tentative approach, Soft Computing, 14: 899-911, (2010).

[25] Metlin, C., Lee, F. and Drago, J., The American cancer society national prostate cancer detection, project: Findings on the detection of early prostate cancer in 2425 men, Cancer, 67: 2949-2958, (1991).

[26] Seker, H., Odetayo, M., Petrovic, D. and Naguib, R.N.G., A fuzzy logic based method for prognostic decision making breast and prostate cancers, IEEE Transactions on Information Technology in Biomedicine, 7: 114-122, (2003). 